\title{
The Effect of Neonatal Maternal Stress on Plasma Levels of Adrenocorticotropic Hormone, Corticosterone, Leptin, and Ghrelin in Adult Male Rats Exposed to Acute Heterotypic Stressor
}

\author{
A. HOLUBOVÁ ${ }^{1}$, A. ŠTOFKOVÁ ${ }^{1}$, J. JURČOVIČOVÁ ${ }^{1}$, R. ŠLAMBEROVÁ ${ }^{1}$ \\ ${ }^{1}$ Department of Normal, Pathological and Clinical Physiology, Third Faculty of Medicine, Charles \\ University, Prague, Czech Republic
}

Received March 25, 2016

Accepted October 26, 2016

\begin{abstract}
Summary
Activation of the hypothalamic-pituitary-adrenal (HPA) axis is important for maintenance of homeostasis during stress. Recent studies have shown a connection between the HPA axis and adipose tissue. The present study investigated the effect of acute heterotypic stress on plasma levels of adrenocorticotropic hormone (ACTH), corticosterone (CORT), leptin, and ghrelin in adult male rats with respect to neonatal maternal social and physical stressors. Thirty rat mothers and sixty of their male progeny were used. Pups were divided into three groups: unstressed control (C), stressed by maternal social stressor (S), stressed by maternal social and physical stressors (SW). Levels of hormones were measured in adult male progeny following an acute swimming stress $(10 \mathrm{~min})$ or no stress. ELISA immunoassay was used to measured hormones. The ACTH and CORT levels were significantly increased in all groups of adult progeny after acute stress; however, CORT levels were significantly lower in both neonatally stressed groups compared to controls. After acute stress, plasma leptin levels were decreased in the $C$ and SW groups but increased in the $S$ group. The data suggest that long-term neonatal stressors lead to lower sensitivity of ACTH receptors in the adrenal cortex, which could be a sign of stress adaptation in adulthood. Acute stress in adult male rats changes plasma levels of leptin differently relative to social or physical neonatal stressors.
\end{abstract}

\section{Key words}

Stress • ACTH • Corticosterone $\bullet$ Leptin • Ghrelin

\section{Corresponding author}

R. Šlamberová, Department of Normal, Pathological and Clinical Physiology, Third Faculty of Medicine, Charles University,
Ke Karlovu 4, 12000 Prague 2, Czech Republic. Fax: +420 224902750. E-mail: romana.slamberova@If3.cuni.cz

\section{Introduction}

Postnatal stress such as child neglect and abuse are associated with impairment of neurological development and may lead to psychiatric disorders in adulthood (Daniels et al. 2004, Heim and Nemeroff 2001, Kessler et al. 1997, Lajud et al. 2012, Marais et al. 2008, Rinne et al. 2002). However, the neurobiological mechanism of adverse early life experiences on the augmented stress susceptibility of affected children is still not fully understood. One of the hypotheses focuses on dysregulation of hypothalamic-pituitary-adrenal (HPA) axis (Lajud et al. 2012, Marais et al. 2008, Mullen et al. 1996). Normal function of the HPA axis is important for the maintenance of homeostasis during stress (Zareian et al. 2011), while constant release of stress hormones by repeated stress is a characteristic sign of adverse health outcomes (Maniam et al. 2014, Marais et al. 2008, McEwen and Gianaros 2010).

Maternal separation, as an animal model, has been studied extensively for more than five decades to describe the effects of early life experience on the HPA axis and behavioral responses (Daniels et al. 2004, Hofer 1973, Lajud et al. 2012, Marais et al. 2008, Pryce and Feldon 2003). Periodic maternal separation is a potent social stressor that may impact and activate the HPA axis response in pups even during the hypo-responsive period (SHRP) that takes place during the first two postnatal weeks (Lajud et al. 2012, Sapolsky and Meaney 1986, 
Zoicas and Neumann 2016). It is suggested that chronic elevations of glucocorticoids, after long-term maternal separation, could impair the hippocampus, which contains high concentrations of mineralocorticoid and glucocorticoid receptors; which could lead to modification in the density of receptors and subsequently to abnormalities of the adult HPA axis regulation (Enthoven et al. 2008, Sapolsky 1985). Thus, maternal separation may alter neuroendocrine and neurotransmitter responses to stressors and, if repeatedly experienced, could produce long-term increases in HPA axis responsiveness, anxiety, depression, and drug abuse in adulthood (Biagini et al. 1998, Daniels et al. 2004, Ladd et al. 1996, Moffett et al. 2007, Plotsky et al. 2005).

Characteristics of stressors can differ, we can distinguish between psychological and physical stressors and most stressors studied in animals are a combination of both (Grissom and Bhatnagar 2009). Therefore, in the present study, rats were exposed to psychological and social stressor represented by maternal separation (O'Connor et al. 2015, Zoicas and Neumann 2016) and a mixture of the social and physical stressors represented by maternal cold water swimming (Drago et al. 1999, Šlamberová et al. 2002). HPA axis activity can also be influenced by rapid changes in the estrous cycle of female rodents (Grissom and Bhatnagar 2009). To prevent any additional influences from the HPA axis, only male offspring were used in the present study.

Recent studies have demonstrated a connection between the HPA axis and adipose tissue (Hernandez et al. 2000, Pralong and Gaillard 2001). There is also evidence that several peripheral metabolic markers, such as leptin and ghrelin, are altered by stressful events such as maternal separation (Salzmann et al. 2004, Schmidt et al. 2006) as well as physical stress (Baltaci et al. 2012, Zareian et al. 2011). However, the effects of physical and social stress on stress and metabolic hormones are extremely variable.

The majority of experimental evidence suggests that long-term maternal separation disrupts the SHRP following increased activity of the HPA axis (Biagini et al. 1998, Ladd et al. 1996, Plotsky et al. 2005). In addition, it is assumed that exposure to any heterotypic stress after HPA habituation to a homotypic long-lasting stress in older rodents elicits facilitation of HPA activity (Armario et al. 1988). In view of all the mentioned facts, the present study hypothesized that early life stress exposure during the postnatal period affects the regulation of the HPA axis, including adrenocorticotropic hormone (ACTH), corticosterone (CORT), leptin, and ghrelin, which cause changes that can persist into adulthood. Our study aimed to investigate the effect of neonatal maternal social and physical stress on plasma levels of ACTH, CORT, leptin and ghrelin after heterotypic stress in adult male rats.

\section{Methods}

\section{Mothers}

Thirty adult albino Wistar female rats were delivered by Velaz (Prague, Czech Republic) from Charles River Laboratories International, Inc. Females (300-350 g) were housed in groups ( 5 per cage) and left undisturbed for a week in a temperature-controlled $\left(22-24^{\circ} \mathrm{C}\right)$ colony room. Animals had free access to food and water and lived on a $12 \mathrm{~h}$ (light) : $12 \mathrm{~h}$ (dark) cycle with lights on at 6:00 am. After one week of acclimatization, females were randomly assigned to three groups, social stressor only (S), social plus physical stressor (SW), and controls (C), i.e. without any kind of stress.

\section{Fertilization}

After a second week of acclimatization female rats were smeared (vaginal lavage) to determine the phase of the estrous cycle. At the onset of the estrous phase of the estrous cycle females were housed overnight with adult males. One female was paired with one male in each cage. The following day females were smeared again to check for the presence of sperm and returned to their previous home cages. The day after impregnation was counted as day 1 of gestation. On day 20 of gestation, females were placed individually in maternity cages (one female per cage). The day each female gave birth was counted as postnatal day (PD) 0 . Mothers and offspring were left undisturbed for the remainder of the day.

\section{Postnatal care}

On PD 1, litter size was adjusted to 12 pups. Whenever possible, equal numbers of males and females were raised by each mother. Stress-exposure was conducted once daily from PD 1 to PD 14. Litters were divided into three groups: controls $(C)$ without any stress exposure; a group with maternal separation (S) as the social stressor; and a group with maternal separation plus maternal cold-water stress (i.e. a combination of social and physical stressor). After day 14, pups and their mothers were left undisturbed without any kind of stress until they were weaned on PD 21. Male offspring were 
then grouped according to neonatal exposure to stress or no stress and left undisturbed until adulthood.

\section{Social stress}

Maternal separation as a social stressor was conducted from PD 1 to PD 14 for $3 \mathrm{~h}$ per day between 8:00-11:00 am (Huot et al. 2004, Lajud et al. 2012, Plotsky et al. 2005). All pups were gently removed from their maternity cage, while the mothers were left undisturbed. Pups were housed in a different room to prevent communication with their mothers via ultrasound vocalizations. The cage with pups was always placed on a heating pad to prevent chilling. After $3 \mathrm{~h}$ of separation pups were returned to their mothers. Control pups were left undisturbed with their mothers.

\section{Physical stress}

Maternal cold water was used as a physical stressor (Drago et al. 1999, Šlamberová et al. 2002). A plastic container $(25 \times 35 \times 40 \mathrm{~cm}, \mathrm{LWH})$ was filled with $5{ }^{\circ} \mathrm{C}$ water to a depth of $25 \mathrm{~cm}$. Rats were weighed and body temperature was monitored daily prior to physical stressing to check their condition. The water temperature was maintained at $5{ }^{\circ} \mathrm{C}$ with ice. Each rat-mother (from the appropriate group) was placed into the cold water and forced to swim for $5 \mathrm{~min}$. After $5 \mathrm{~min}$, rats were towel-dried and placed under a heating lamp until they were mostly dry. Then they were returned to their home cages. The water in the containers was cleaned of released feces after each animal.

\section{Acute swimming stress}

Exposure to cold environments, social stress or forced swim leads to facilitation of the HPA axis response to novelty or restraint (Grissom and Bhatnagar 2009). While we used the maternal separation as social stressor and cold water as physical stress of the mother during the early postnatal period, heterotypic stressor, forced swimming, was used in adult offspring. The milder stress was used because studies show that individuals exposed to the stress prenatally or early postnatally are more sensitive to the stress in adulthood (Francis et al. 1999, Heim and Nemeroff 2001, Mastorci et al. 2009, Šlamberová et al. 2002). A total of 60 adult male offspring were used in this experiment. Only two male offspring were used from each litter to avoid litter bias. The other offspring were used in other studies. Adult male progeny (PD 70-80) were divided into six groups $(n=10)$ according their exposure to neonatal stress: 3 stressed groups (stressed through acute swimming for $10 \mathrm{~min}, \mathrm{C}+, \mathrm{S}+, \mathrm{SW}+$ ) and 3 unstressed groups (C-, S-, SW-), which were used for baseline values. Rats were weighed for the three days just prior to testing. Additionally, food and water intake was monitored during the two days prior to analyses. For acute swimming stress, the same plastic container ( $25 \times 35 \times 40 \mathrm{~cm}, \mathrm{LWH})$, which was used for maternal physical stress, was filled with room-temperature water $\left(+25^{\circ} \mathrm{C}\right)$. Rats were placed individually in the water and allowed to swim for $10 \mathrm{~min}$. The water was cleaned or changed between animals as necessary.

\section{Sample collection}

At the end of the swimming period rats were gently dried before collecting blood samples. Immediately after the acute stress each animal was decapitated and trunk blood was collected into tubes containing EDTA for determination of CORT, or EDTA with protease inhibitors (aprotinin and pefabloc) for determination of ACTH, leptin, and ghrelin. Blood was centrifuged to obtain plasma and plasma aliquots for ghrelin assay were acidified with $\mathrm{HCl}$ to $0.05 \mathrm{~N}$ to prevent ghrelin degradation. Hormone levels were measured by enzyme-linked immunosorbent assay (ELISA) kits: ACTH, Phoenix Pharmaceuticals (Burlingame, CA); CORT, Immunodiagnostic System (Boldon, UK); leptin and the active isoform of ghrelin, EMD Millipore Corporation (Billerica, MA).

\section{Statistical analyses}

After testing data for normal distribution, One-way ANOVA (Stress exposure) was used to analyze the level of ACTH, CORT, leptin, and ghrelin among all groups. Fisher's test was used for post-hoc test comparisons. Differences were considered significant if $\mathrm{p}<0.05$. Data were expressed in graphs as means \pm SEM.

\section{Results}

Baseline values of ACTH and CORT were without significant differences among all groups. The $\mathrm{ACTH}\left[F_{(5,52)}=21.90 ; \mathrm{p}<0.001\right]$ and $\operatorname{CORT}\left[F_{(5,54)}=61.62\right.$; $\mathrm{p}<0.001]$ levels were greatly increased in all acute stressed groups of adult progeny $(\mathrm{C}+, \mathrm{S}+, \mathrm{SW}+)$ in comparison with controls (C-, S-, SW-) (Fig. 1). There were significant differences between levels of stress hormones relative to neonatal treatment. After acute swimming stress, the neonatal stressed SW+ group 
showed significantly higher ACTH levels compared to the control $\mathrm{C}+$ group $\left[F_{(5,52)}=21.90 ; \mathrm{p}<0.001\right]$. Significant difference also occurred between the social stressed $\mathrm{S}+$ group and the social and physical stressed $\mathrm{SW}+$ group
$\left[F_{(5,52)}=21.90 ; \mathrm{p}<0.05\right]$. Both long-term neonatal stressed groups $\mathrm{S}+\left[F_{(5,54)}=61.62 ; \mathrm{p}<0.01\right], \mathrm{SW}+\left[F_{(5,54)}=61.62\right.$; $\mathrm{p}<0.001]$ also showed significantly lower levels of CORT in adulthood in comparison with the control $\mathrm{C}+$ group.
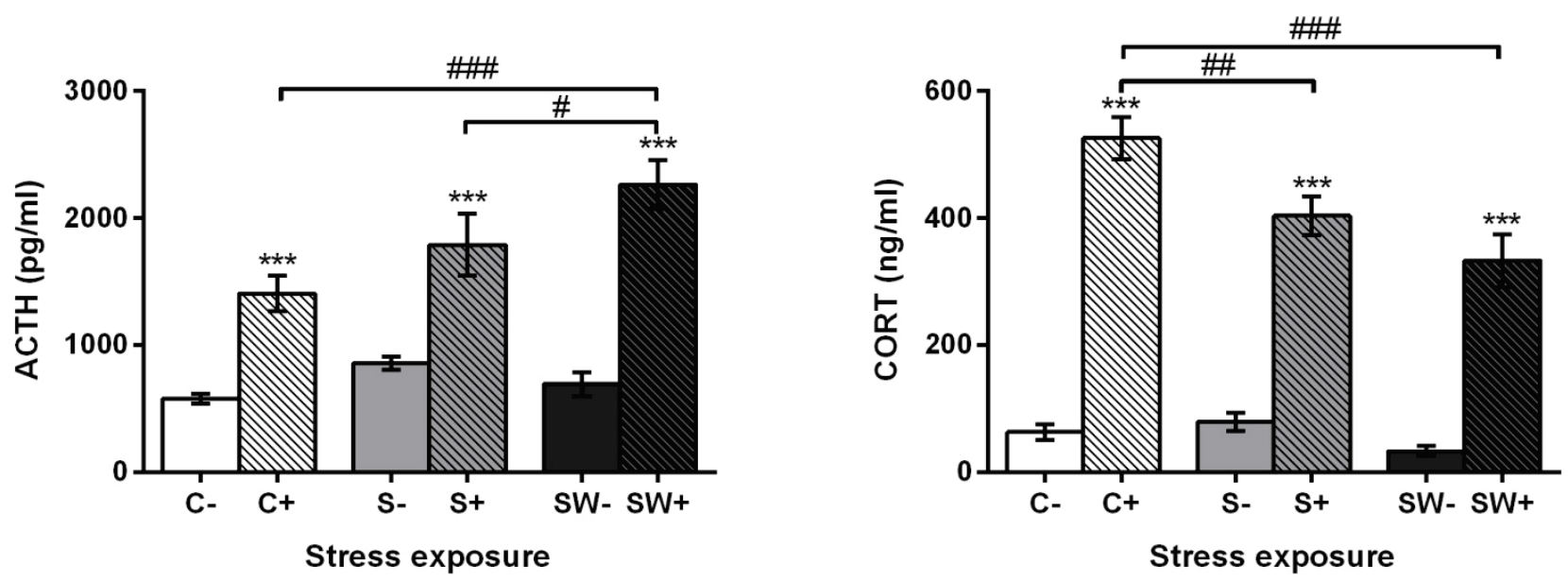

Fig. 1. The effect of acute swimming stress on plasma levels of ACTH and CORT according to neonatal stress in male progeny. Values are means \pm SEM. C - control, S - maternal separation, SW - maternal separation with cold water swimming, $\mathrm{C}+, \mathrm{S}+, \mathrm{SW}+-$ rats with acute swimming stress, C-, S-, SW- - rats with no acute swimming stress in adulthood. $* * * p<0.0001$ stressed group $(\mathrm{C}+, \mathrm{S}+, \mathrm{SW}+)$ vs. non-stressed group ( $\mathrm{C}-\mathrm{S}, \mathrm{S}-\mathrm{S}$ S-) of adult male progeny. \# $\mathrm{p}<0.05, \# \# \mathrm{p}<0.01, \# \# \# \mathrm{p}<0.001$ significant differences among all treatments.
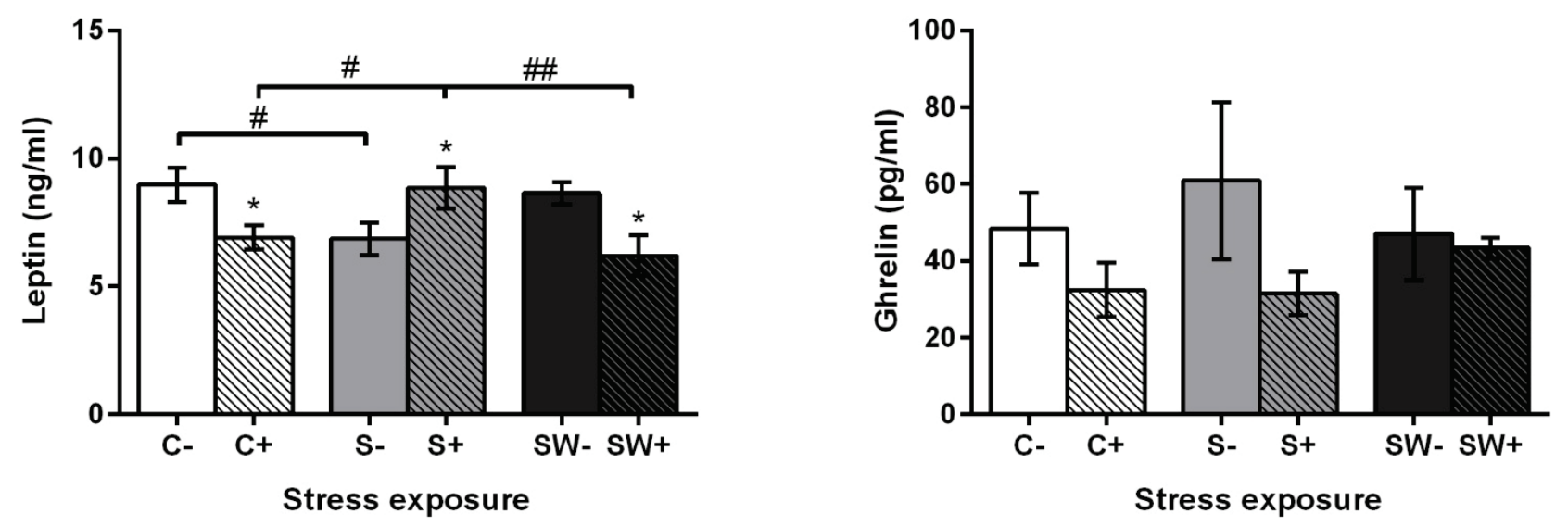

Fig. 2. The effect of acute swimming stress on plasma levels of leptin and ghrelin according to neonatal stress in male progeny. Values are means \pm SEM. C - control, S - maternal separation, SW - maternal separation with cold water swimming, $\mathrm{C}+$, S+, SW+ - rats with acute swimming stress, C-, S-, SW- - rats with no acute swimming stress in adulthood. * $p<0.05$ stressed group $(C+, S+$, SW+) vs. non-stressed group (C-, S-, SW-) of adult male progeny. \# $\mathrm{p}<0.05$, \#\# $\mathrm{p}<0.01$ significant differences among all treatments.

Acute swimming stress decreased levels of leptin in the adult male progeny in control $\mathrm{C}+$ group and in the SW+ group, which were exposed to both stressors during the neonatal period $\left[F_{(5,54)}=3.49 ; \mathrm{p}<0.05\right]$ (Fig. 2). On the other hand, rats stressed by maternal separation $(\mathrm{S}+)$ had significantly higher levels of plasma leptin compared to non-acute stressed (S-) rats $\left[F_{(5,54)}=3.49\right.$; $\mathrm{p}<0.05]$. There were also differences between the socially stressed S+ group and the other tested groups. Specifically, in the control C+ group $\left[F_{(5,54)}=3.49\right.$; $\mathrm{p}<0.05]$ and the $\mathrm{SW}+$ group $\left[F_{(5,54)}=3.49 ; \mathrm{p}<0.01\right]$. There were significantly lower levels of leptin than in $\mathrm{S}+$ group. There were no significant changes of plasma ghrelin level in any of the groups.

The measurement of food and water intake before the experiment did not reveal any relevant changes. However, weight was significantly lower in the group of adult male rats that were postnatally stressed by maternal separation (S) only, in comparison to the $\mathrm{C}\left[F_{(2,34)}=6.01\right.$; $\mathrm{p}<0.01]$ and $\mathrm{SW}\left[F_{(2,34)}=6.01 ; \mathrm{p}<0.05\right]$ groups (Fig. 3). 


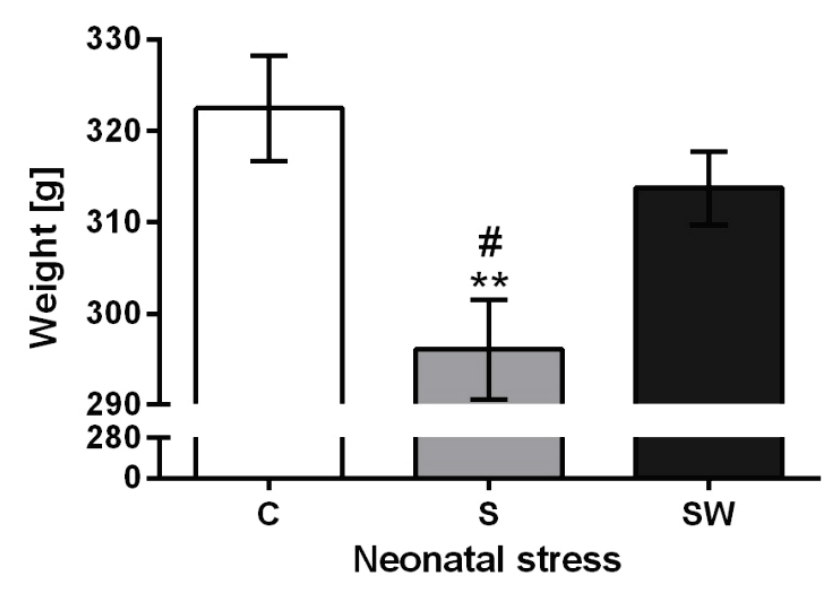

Fig. 3. Average weight of adult male progeny from the three days prior to experimentation. Values are means \pm SEM. C - control, S - maternal separation, SW - maternal separation with cold water swimming. $* * p<0.01$ significant difference between the $\mathrm{S}$ and $\mathrm{C}$ group. \# $\mathrm{p}<0.05$ significant difference between the $S$ and SW group.

\section{Discussion}

Adverse experiences through physical or psychological means or synthetic glucocorticoid administration can permanently alter the HPA axis function (Ivy et al. 2008, Sapolsky and Meaney 1986). It is assumed that long-term postnatal stress induces dysregulation of the HPA axis through hypersecretion of stress hormones (Biagini et al. 1998, Ladd et al. 1996, Marais et al. 2008, Plotsky et al. 2005) and that additional exposure to heterotypic stress facilitates the stress response later in life (Armario et al. 1988). Thus, we expected that exposure to acute heterotypic stress in adulthood would increase the plasma levels of ACTH and CORT in postnatally stressed groups based on the assumption that the stronger the postnatal stress the higher the levels of stress hormones. Since there is evidence for a connection between the HPA axis and leptin and ghrelin (Hernandez et al. 2000, Pralong and Gaillard 2001, van der Lely et al. 2004) we also expected that there would be a connection between stress and metabolic hormones. In spite of these expectations, our data showed a significant reduction in CORT after acute stress in the postnatally stressed group of adult rats compared to controls. Although no significant changes in concentrations of ghrelin were observed, our data show that acute swimming stress affects plasma levels of leptin differently depending on the type of postnatal stressors.

Increased plasma levels of ACTH and decreased plasma levels of CORT were observed after acute stress in the group of pups exposed to social $(\mathrm{S}+)$ as well as social and physical $(\mathrm{SW}+)$ stress in comparison to the postnatally unstressed controls $(\mathrm{C}+)$. Our data therefore suggest that long-term neonatal stress leads to lower sensitivity of ACTH receptors in the adrenal cortex, which could be due to adaptation to subsequent stressful experiences. Our data are consistent with the work of Daskalakis et al. (2011) where newborn rats were separated for $8 \mathrm{~h}$ a day for 3 days (from PD 3 to PD 5) and then exposed to a novel stress. Contrary to a single maternal separation, if the pups had been exposed repeatedly to daily separation, the rise in CORT was abolished. Rat pups repeatedly separated into a novel environment were also adapted to additional novel stress. Thus, the previous experience of maternal separation into a novel environment prepares the pups for other novel experiences (Daskalakis et al. 2011). Furthermore, there is evidence showing no facilitation of the HPA axis to novel environments in adult animals repeatedly exposed to homotypic stressors (noise and restraint) compared to control animals (Babb et al. 2014). Individuals are able to adapt to the environmental conditions to which they were exposed and to improve their resilience and ability to cope with such situations (Grissom and Bhatnagar 2009). There is also supporting evidence showing that HPA adaptation to repeated stress is long-lasting, i.e. persisting after 3-4 weeks (Bhatnagar et al. 2002, Nyhuis et al. 2010). A study of Rabasa et al. (2015) demonstrated a reduction of the HPA response to repeated immobilization in adult rats that was still observed after two months. Our results support the observations that adaptation of the HPA axis to neonatal stressors could be long-lasting in rats, persisting until adulthood.

On the other hand, our present study seems to contradict other works that showed exaggerated adrenocortical responses to heterotypic stress (air-puffstartle) in adult rats after $3 \mathrm{~h} /$ day maternal separation from PD 2 to PD 14, resulting from decreased glucocorticoid negative feedback compared to rats with handling (Huot et al. 2004, Ladd et al. 2004). However, these studies compared the maternal separation group with a group of rats that were handled, which is known to improve coping ability with regard to stress experience in later life (Pardon and Rattray 2008). Therefore, the difference between these studies and the present study might be due to the distinct treatment methods. Adaptation and the desensitization of adrenocortical output could also lie in whether the pups were separated (daily) in a home or unfamiliar (novel) environment (Daskalakis et al. 2011). 
Other possible explanations of our results are described by Cyr and Romero (2009). With regard to physiological desensitization, the animal may still experience stress despite a reduced release of primary stress mediators and thus the insult could be noxious. There is also a theory of exhaustion, where the stress response can no longer be maintained due to increased fatigue and as a result concentrations of stress hormones, such as glucocorticoids, are decreased (Cyr and Romero 2009). Regardless, physiological desensitization or exhaustion are both associated with a lower baseline of primary stress mediators compared to those in non-stressed animals (Cyr and Romero 2009). Thus, our results challenge these hypotheses since they revealed no changes in baseline ACTH or CORT in any of the groups. Other hypotheses focus on maternal care, which can significantly affect responsivity of the HPA axis in adult offspring (Meaney 2001). The assumption is that the time spent by the dam away from her pups evokes changes in her behavior that disrupts their ability to provide adequate maternal care (Huot et al. 2004). In the present study, maternal behavior was not specifically observed as part of the experimental protocol.

In comparison to the leptin baseline, acute stress decreased plasma leptin levels in the $\mathrm{C}+$ group as well as in $\mathrm{SW}+$ group. It is assumed that physical activity such as acute swim stress could be the reason for the decreased circulating levels of plasma leptin in our study. This is supported by a study by Pagano et al. (1999) that reported a strong relationship between swimming exercise and circulating leptin, in which plasma leptin was decreased by up to $30 \%$ following exercise in normal rats. Many other animal studies (Baltaci et al. 2012) as well as reports on swimmers and marathoners (Karamouzis et al. 2002, Zaccaria et al. 2002) have noted reduced plasma leptin levels immediately after exercise. However, there are some studies that found either increased concentrations (Flores et al. 2006, Zareian et al. 2011) or no changes in plasma leptin levels after exercise (Borg et al. 2014).

Interestingly, the level of leptin significantly rose in the $\mathrm{S}+$ group after acute stress compared with the baseline (S-) and other groups, e.g. $\mathrm{C}+$ and $\mathrm{SW}+$, after acute stress. Thus, neonatal social stress seems to play a more important part in leptin secretion than does imminent physical activity. The inverse effect was observed in the SW group suggesting that long-term neonatal physical stressors outweighed the influence of maternal separation. Also leptin baseline in the S- group was significantly decreased in comparison with the C- group, which is in agreement with recent studies reporting a reduction in leptin following maternal separation (Salzmann et al. 2004, Schmidt et al. 2006, Walker et al. 2004). This could be due to reduced maternal food intake, which was observed after neonatal separation (Salzmann et al. 2004). This could explain our data where the weight of group $\mathrm{S}$ was significantly lower than group $\mathrm{C}$ and $\mathrm{SW}$. A body weight (fat mass) reduction was associated with a fall in leptin levels that stimulated the appetite until fat mass was restored (Friedman 2011). Nevertheless, there were no significant differences in food intake among any of the groups of adult rats before the experiment.

Our data revealed no correlation between stress and the measured metabolic hormones. This is in agreement with recent studies that found no correlations between changes in plasma leptin level and stimulation of glucocorticoids (Perello et al. 2006, Zareian et al. 2011). Nonetheless, there are studies that have shown a connection between the HPA axis and adipose tissue, where glucocorticoids and possibly ACTH can stimulate leptin secretion by adipocytes (Hernandez et al. 2000, Pralong and Gaillard 2001, Spinedi and Gaillard 1998) and that circulating leptin can inhibit secretion of CORT (Ahima et al. 1998, Bornstein et al. 1997, Pralong and Gaillard 2001, Salzmann et al. 2004).

We observed no significant changes in plasma ghrelin levels in any of the groups. This result conflicts the finding that ghrelin may have a role in mediating neuroendocrine and behavioral responses to stressors via alteration of corticotropin-releasing hormone (CRH) mRNA expression in the hypothalamus (van der Lely et al. 2004). Nevertheless, there are studies that focused on acute physical activity that found no correlation between ghrelin levels and physical activity (Borg et al. 2014, Burns et al. 2007, Martins et al. 2007, Schmidt et al. 2004). Thus, changes in ghrelin secretion appear to be relatively insensitive to acute physical stress.

In conclusion, stress during early life is not necessarily pathological, instead it may have adaptive value to an individual that faces stressful situations during adulthood (Santarelli et al. 2014). Our data revealed a significant reduction in the responsiveness to stress by the adrenal cortex of adult male rats following neonatal exposure to social and/or physical stressors. We suggest that long-term maternal separation of pups into a novel environment might lead to adaptation manifested by desensitization of adrenocortical CORT output in 
adulthood. Our data also suggest that the effect of maternal separation alone in the neonatal stage can be an important modulating factor for secretion of leptin in adulthood. In everyday life, the children of drug-addicted mothers are often neglected. These mothers often fail to take good care of their child or children, which can result in increased anxiety, an altered stress response, and changes in social behavior. Our previous studies have shown that methamphetamine administered to female rats during pregnancy and/or lactation resulted in a deterioration of maternal behavior (Šlamberová et al. 2005a, Šlamberová et al. 2005b) and led to changes in anxiety and social behavior in adult offspring (Šlamberová et al. 2015a, Šlamberová et al. 2015b). Future studies are planned to investigate changes after perinatal social and physical stress in drug-addicted rat mothers and their offspring.

\section{Conflict of Interest}

There is no conflict of interest.

\section{Acknowledgements}

This study was supported by research program \# PRVOUK P34 and project \# 260277/SVV/2016 from Charles University. The authors express their appreciation to Thomas Ownsby Secrest, M.Sc. for critical reading and editing of the manuscript. The procedures for animal experimentation utilized in this study were reviewed and approved by the Institutional Animal Care and Use Committee and are in agreement with the Czech Government Requirements under the Policy of Human Care of Laboratory Animals (No. 246/1992) and with subsequent regulations by the Ministry of Agriculture of the Czech Republic (No. 311/1997).

\section{References}

AHIMA RS, PRABAKARAN D, FLIER JS: Postnatal leptin surge and regulation of circadian rhythm of leptin by feeding. Implications for energy homeostasis and neuroendocrine function. J Clin Invest 101: 1020-1027, 1998.

ARMARIO A, HIDALGO J, GIRALT M: Evidence that the pituitary-adrenal axis does not cross-adapt to stressors: comparison to other physiological variables. Neuroendocrinology 47: 263-267, 1988.

BABB JA, MASINI CV, DAY HE, CAMPEAU S: Habituation of hypothalamic-pituitary-adrenocortical axis hormones to repeated homotypic stress and subsequent heterotypic stressor exposure in male and female rats. Stress $\mathbf{1 7}$ : 224-234, 2014.

BALTACI AK, VURUCU N, UZUN A, MOGULKOC R, KILIC M: The effect of acute swimming exercise on plasma leptin in rats. Bratisl Lek Listy 113: 592-594, 2012.

BHATNAGAR S, HUBER R, NOWAK N, TROTTER P: Lesions of the posterior paraventricular thalamus block habituation of hypothalamic-pituitary-adrenal responses to repeated restraint. J Neuroendocrinol 14: 403-410, 2002.

BIAGINI G, PICH EM, CARANI C, MARRAMA P, AGNATI LF: Postnatal maternal separation during the stress hyporesponsive period enhances the adrenocortical response to novelty in adult rats by affecting feedback regulation in the CA1 hippocampal field. Int J Dev Neurosci 16: 187-197, 1998.

BORG ML, ANDREWS ZB, WATT MJ: Exercise training does not enhance hypothalamic responsiveness to leptin or ghrelin in male mice. $J$ Neuroendocrinol 26: 68-79, 2014.

BORNSTEIN SR, UHLMANN K, HAIDAN A, EHRHART-BORNSTEIN M, SCHERBAUM WA: Evidence for a novel peripheral action of leptin as a metabolic signal to the adrenal gland: leptin inhibits cortisol release directly. Diabetes 46: 1235-1238, 1997.

BURNS SF, BROOM DR, MIYASHITA M, MUNDY C, STENSEL DJ: A single session of treadmill running has no effect on plasma total ghrelin concentrations. J Sports Sci 25: 635-642, 2007.

CYR NE, ROMERO LM: Identifying hormonal habituation in field studies of stress. Gen Comp Endocrinol 161: 295-303, 2009.

DANIELS WM, PIETERSEN CY, CARSTENS ME, STEIN DJ: Maternal separation in rats leads to anxiety-like behavior and a blunted ACTH response and altered neurotransmitter levels in response to a subsequent stressor. Metab Brain Dis 19: 3-14, 2004. 
DASKALAKIS NP, CLAESSENS SE, LABOYRIE JJ, ENTHOVEN L, OITZL MS, CHAMPAGNE DL, DE KLOET ER: The newborn rat's stress system readily habituates to repeated and prolonged maternal separation, while continuing to respond to stressors in context dependent fashion. Horm Behav 60: 165-176, 2011.

DRAGO F, DI LEO F, GIARDINA L: Prenatal stress induces body weight deficit and behavioural alterations in rats: the effect of diazepam. Eur Neuropsychopharmacol 9: 239-245, 1999.

ENTHOVEN L, DE KLOET ER, OITZL MS: Differential development of stress system (re)activity at weaning dependent on time of disruption of maternal care. Brain Res 1217: 62-69, 2008.

FLORES MB, FERNANDES MF, ROPELLE ER, FARIA MC, UENO M, VELLOSO LA, SAAD MJ, CARVALHEIRA JB: Exercise improves insulin and leptin sensitivity in hypothalamus of Wistar rats. Diabetes 55: 2554-2561, 2006.

FRANCIS DD, CALDJI C, CHAMPAGNE F, PLOTSKY PM, MEANEY MJ: The role of corticotropin-releasing factor-norepinephrine systems in mediating the effects of early experience on the development of behavioral and endocrine responses to stress. Biol Psychiatry 46: 1153-1166, 1999.

FRIEDMAN JM: Leptin and the regulation of body weigh. Keio J Med 60: 1-9, 2011.

GRISSOM N, BHATNAGAR S: Habituation to repeated stress: get used to it. Neurobiol Learn Mem 92: 215-224, 2009.

HEIM C, NEMEROFF CB: The role of childhood trauma in the neurobiology of mood and anxiety disorders: preclinical and clinical studies. Biol Psychiatry 49: 1023-1039, 2001.

HERNANDEZ C, SIMO R, CHACON P, SABIN P, BAENA JA, CASTELLANOS JM, PLANAS M: Influence of surgical stress and parenteral nutrition on serum leptin concentration. Clin Nutr 19: 61-64, 2000.

HOFER MA: Maternal separation affects infant rats' behavior. Behav Biol 9: 629-633, 1973.

HUOT RL, GONZALEZ ME, LADD CO, THRIVIKRAMAN KV, PLOTSKY PM: Foster litters prevent hypothalamic-pituitary-adrenal axis sensitization mediated by neonatal maternal separation. Psychoneuroendocrinology 29: 279-289, 2004.

IVY AS, BRUNSON KL, SANDMAN C, BARAM TZ: Dysfunctional nurturing behavior in rat dams with limited access to nesting material: a clinically relevant model for early-life stress. Neuroscience 154: 1132-1142, 2008.

KARAMOUZIS I, KARAMOUZIS M, VRABAS IS, CHRISTOULAS K, KYRIAZIS N, GIANNOULIS E, MANDROUKAS K: The effects of marathon swimming on serum leptin and plasma neuropeptide Y levels. Clin Chem Lab Med 40: 132-136, 2002.

KESSLER L, WIESEL ML, BOUDJEMA K, MEYER C, LUTUN E, MOULIN B, CAZENAVE JP, WOLF P, PINGET M: Potential role of von Willebrand factor in pancreatic venous thrombosis in simultaneous kidney and pancreas transplantation. Transplant Proc 29: 2418-2419, 1997.

LADD CO, OWENS MJ, NEMEROFF CB: Persistent changes in corticotropin-releasing factor neuronal systems induced by maternal deprivation. Endocrinology 137: 1212-1218, 1996.

LADD CO, HUOT RL, THRIVIKRAMAN KV, NEMEROFF CB, PLOTSKY PM: Long-term adaptations in glucocorticoid receptor and mineralocorticoid receptor mRNA and negative feedback on the hypothalamopituitary-adrenal axis following neonatal maternal separation. Biol Psychiatry 55: 367-375, 2004.

LAJUD N, ROQUE A, CAJERO M, GUTIERREZ-OSPINA G, TORNER L: Periodic maternal separation decreases hippocampal neurogenesis without affecting basal corticosterone during the stress hyporesponsive period, but alters HPA axis and coping behavior in adulthood. Psychoneuroendocrinology 37: 410-420, 2012.

MANIAM J, ANTONIADIS C, MORRIS MJ: Early-life stress, HPA axis adaptation, and mechanisms contributing to later health outcomes. Front Endocrinol (Lausanne) 5: 73, 2014.

MARAIS L, VAN RENSBURG SJ, VAN ZYL JM, STEIN DJ, DANIELS WM: Maternal separation of rat pups increases the risk of developing depressive-like behavior after subsequent chronic stress by altering corticosterone and neurotrophin levels in the hippocampus. Neurosci Res 61: 106-112, 2008.

MARTINS C, MORGAN LM, BLOOM SR, ROBERTSON MD: Effects of exercise on gut peptides, energy intake and appetite. $J$ Endocrinol 193: 251-258, 2007.

MASTORCI F, VICENTINI M, VILTART O, MANGHI M, GRAIANI G, QUAINI F, MEERLO P, NALIVAIKO E, MACCARI S, SGOIFO A: Long-term effects of prenatal stress: changes in adult cardiovascular regulation and sensitivity to stress. Neurosci Biobehav Rev 33: 191-203, 2009. 
MCEWEN BS, GIANAROS PJ: Central role of the brain in stress and adaptation: links to socioeconomic status, health, and disease. Ann N Y Acad Sci 1186: 190-222, 2010.

MEANEY MJ: Maternal care, gene expression, and the transmission of individual differences in stress reactivity across generations. Annu Rev Neurosci 24: 1161-1192, 2001.

MOFFETT MC, VICENTIC A, KOZEL M, PLOTSKY P, FRANCIS DD, KUHAR MJ: Maternal separation alters drug intake patterns in adulthood in rats. Biochem Pharmacol 73: 321-330, 2007.

MULLEN PE, MARTIN JL, ANDERSON JC, ROMANS SE, HERBISON GP: The long-term impact of the physical, emotional, and sexual abuse of children: a community study. Child Abuse Negl 20: 7-21, 1996.

NYHUIS TJ, SASSE SK, MASINI CV, DAY HE, CAMPEAU S: Lack of contextual modulation of habituated neuroendocrine responses to repeated audiogenic stress. Behav Neurosci 124: 810-820, 2010.

O'CONNOR RM, MOLONEY RD, GLENNON J, VLACHOU S, CRYAN JF: Enhancing glutamatergic transmission during adolescence reverses early-life stress-induced deficits in the rewarding effects of cocaine in rats. Neuropharmacology 99: 168-176, 2015.

PAGANO C, MARZOLO M, GRANZOTTO M, RICQUIER D, FEDERSPIL G, VETTOR R: Acute effects of exercise on circulating leptin in lean and genetically obese fa/fa rats. Biochem Biophys Res Commun 255: 698-702, 1999.

PARDON MC, RATTRAY I: What do we know about the long-term consequences of stress on ageing and the progression of age-related neurodegenerative disorders? Neurosci Biobehav Rev 32: 1103-1120, 2008.

PERELLO M, CHACON F, CARDINALI DP, ESQUIFINO AI, SPINEDI E: Effect of social isolation on 24-h pattern of stress hormones and leptin in rats. Life Sci 78: 1857-1862, 2006.

PLOTSKY PM, THRIVIKRAMAN KV, NEMEROFF CB, CALDJI C, SHARMA S, MEANEY MJ: Long-term consequences of neonatal rearing on central corticotropin-releasing factor systems in adult male rat offspring. Neuropsychopharmacology 30: 2192-2204, 2005.

PRALONG FP, GAILLARD RC: Neuroendocrine effects of leptin. Pituitary 4: 25-32, 2001.

PRYCE CR, FELDON J: Long-term neurobehavioural impact of the postnatal environment in rats: manipulations, effects and mediating mechanisms. Neurosci Biobehav Rev 27: 57-71, 2003.

RABASA C, GAGLIANO H, PASTOR-CIURANA J, FUENTES S, BELDA X, NADAL R, ARMARIO A: Adaptation of the hypothalamus-pituitary-adrenal axis to daily repeated stress does not follow the rules of habituation: a new perspective. Neurosci Biobehav Rev 56: 35-49, 2015.

RINNE T, DE KLOET ER, WOUTERS L, GOEKOOP JG, DERIJK RH, VAN DEN BRINK W: Hyperresponsiveness of hypothalamic-pituitary-adrenal axis to combined dexamethasone/corticotropin-releasing hormone challenge in female borderline personality disorder subjects with a history of sustained childhood abuse. Biol Psychiatry 52: 1102-1112, 2002.

SALZMANN C, OTIS M, LONG H, ROBERGE C, GALLO-PAYET N, WALKER CD: Inhibition of steroidogenic response to adrenocorticotropin by leptin: implications for the adrenal response to maternal separation in neonatal rats. Endocrinology 145: 1810-1822, 2004.

SANTARELLI S, LESUIS SL, WANG XD, WAGNER KV, HARTMANN J, LABERMAIER C, SCHARF SH, MULLER MB, HOLSBOER F, SCHMIDT MV: Evidence supporting the match/mismatch hypothesis of psychiatric disorders. Eur Neuropsychopharmacol 24: 907-918, 2014.

SAPOLSKY RM: Glucocorticoid toxicity in the hippocampus: temporal aspects of neuronal vulnerability. Brain Res 359: 300-305, 1985.

SAPOLSKY RM, MEANEY MJ: Maturation of the adrenocortical stress response: neuroendocrine control mechanisms and the stress hyporesponsive period. Brain Res 396: 64-76, 1986.

SCHMIDT A, MAIER C, SCHALLER G, NOWOTNY P, BAYERLE-EDER M, BURANYI B, LUGER A, WOLZT M: Acute exercise has no effect on ghrelin plasma concentrations. Horm Metab Res 36: 174-177, 2004.

SCHMIDT MV, LEVINE S, ALAM S, HARBICH D, STERLEMANN V, GANEA K, DE KLOET ER, HOLSBOER F, MULLER MB: Metabolic signals modulate hypothalamic-pituitary-adrenal axis activation during maternal separation of the neonatal mouse. J Neuroendocrinol 18: 865-874, 2006.

SPINEDI E, GAILLARD RC: A regulatory loop between the hypothalamo-pituitary-adrenal (HPA) axis and circulating leptin: a physiological role of ACTH. Endocrinology 139: 4016-4020, 1998. 
ŠLAMBEROVÁ R, SCHINDLER CJ, VATHY I: Impact of maternal morphine and saline injections on behavioral responses to a cold water stressor in adult male and female progeny. Physiol Behav 75: 723-732, 2002.

ŠLAMBEROVÁ R, CHAROUSOVÁ P, POMETLOVÁ M: Maternal behavior is impaired by methamphetamine administered during pre-mating, gestation and lactation. Reprod Toxicol 20: 103-110, 2005a.

ŠLAMBEROVÁ R, CHAROUSOVÁ P, POMETLOVÁ M: Methamphetamine administration during gestation impairs maternal behavior. Dev Psychobiol 46: 57-65, 2005b.

ŠLAMBEROVÁ R, MIKULECKÁ A, MACÚCHOVÁ E, HREBÍČKOVÁ I, ŠEVČÍKOVÁ M, NOHEJLOVÁ K, POMETLOVÁ M: Effects of psychostimulants on social interaction in adult male rats. Behav Pharmacol 26: 776-785, 2015a.

ŠLAMBEROVÁ R, POMETLOVÁ M, MACÚCHOVÁ E, NOHEJLOVÁ K, STUCHLÍK A, VALEŠ K: Do the effects of prenatal exposure and acute treatment of methamphetamine on anxiety vary depending on the animal model used? Behav Brain Res 292: 361-369, 2015 b.

VAN DER LELY AJ, TSCHOP M, HEIMAN ML, GHIGO E: Biological, physiological, pathophysiological, and pharmacological aspects of ghrelin. Endocr Rev 25: 426-457, 2004.

WALKER CD, SALZMANN C, LONG H, OTIS M, ROBERGE C, GALLO-PAYET N: Direct inhibitory effects of leptin on the neonatal adrenal and potential consequences for brain glucocorticoid feedback. Endocr Res 30: $837-844,2004$.

ZACCARIA M, ERMOLAO A, ROI GS, ENGLARO P, TEGON G, VARNIER M: Leptin reduction after endurance races differing in duration and energy expenditure. Eur J Appl Physiol 87: 108-111, 2002.

ZAREIAN P, KARIMI MV, DORNEYANI G: The comparison of the effects of acute swimming stress on plasma corticosterone and leptin concentration in male and female rats. Acta Med Iran 49: 284-287, 2011.

ZOICAS I, NEUMANN ID: Maternal separation facilitates extinction of social fear in adult male mice. Behav Brain Res 297: 323-328, 2016. 